\title{
Valorisation of food waste as new raw materials in broiler feed
}

\author{
Latifa MECHKIRROU ${ }^{1,2^{*}}$, Mohammed OUHSSINE ${ }^{1}$, and Mohamed El Amine AFILAL ${ }^{2}$ \\ ${ }^{1}$ Laboratory of Agro-Physiology, Biotechnologies, Environment and Qualities, Faculty of Sciences, PB 242 14000, Kenitra, Morocco \\ ${ }^{2}$ Laboratory of bioresources, biotechnologies, Ethnopharmacology and Health, Faculty of Sciences, PB 717 60000, Oujda, Morocco
}

\begin{abstract}
In Morocco, the food waste fraction constitutes a large part of the total municipal solid waste generated. In order to promote this fraction as a feed source for poultry, a study was carried out to evaluate its digestive and metabolic effects, as well as its nutritional value on broilers. Indeed, comparative tests were carried out on two separate batches of small broilers fed, successively, with a commercial compound feed (CCF), and a feed prepared in the laboratory using kitchen waste as a substitute (LPF). The results obtained throughout the rearing period revealed the feasibility of the valorization of food waste as a substitute promoted in the poultry feed sector. In addition, the prefabricated feeds gave the same feed consumption index (1.03), compared to the commercial compound feed applied in the same rearing farm, while the weight gain index results were more advantageous for FPL. The study demonstrates the valorisation of feed waste as a new substitute for poultry feed.
\end{abstract}

\section{INTRODUCTION}

Population growth, urban sprawl, socio-economic activity, and the lifestyles and consumption habits of citizens all contribute to the generation of huge amounts of waste and the accumulation of landfills in urban and rural areas [1]. Indeed, the management of these large quantities of household solid waste (MSW) generated in recent years has been a serious environmental and socioeconomic challenge for Morocco [2].

In terms of quantity, MSW production exceeds 9 million tons per year, with a daily ratio of $0.76 \mathrm{~kg}$ per person in urban areas, recycling of which is only $9 \%$ and $37 \%$ of this waste is destined for landfills $[3,4]$. While the organic fraction of this waste is about $65 \%$, or nearly 6 million tons per year [1]. In fact, these amounts of food waste (FW), which are most often generated by households, hotels, supermarkets and restaurants [5], have a very high nutritional value hence the possibility of valuing them as food for pigs and poultry [6].

Since organic waste with edible portions greater than $80 \%$ is inevitably produced, the generated FW is highly recommended to be more effectively evaluated than buried as MSW [7]. Certainly, compared to composting and anaerobic digestion, one of the methods of valuing FW suggested would be their use in cattle rearing. This can help meet the meat needs across the country $[8,9]$. Besides, the poultry sector in Morocco is in full growth, thus, the level of national poultry meat production is estimated at 490000 tons in 2009 and 510000 tons in 2010 , covering $100 \%$ of national demand [10].

As a result, the expansion of the poultry sector with a fastgrowing production causes a high request in terms of poultry feed, which can negatively impact human food resource balance, certainly, with several ineffective attempts to treat and enhance these household wastes, following an ordinary process such as landfilling combined with the methane gas withdrawal [1].

The valorisation of these wastes, especially the food fraction, in substitute food chains in various sectors remains an aspect of great potentiality, which at this time is not realized. Therefore, the use of wet food waste was the most beneficial to the environment followed by dry food. Certainly, this is because this type of waste has been used to replace other conventional foods, for example, the incorporation of this fraction into swine diets could support $20 \%$ of the EU's pig production. Indeed, one ton of wet food waste could replace $109.5 \mathrm{~kg}$ of pig feed [9]. Likewise, the food waste recovery, including its drying costs and associated emissions contribute not only to the reduction of conventional feed inputs but also, to the overall environmental footprint of livestock feed [8]. In addition, an experiment proved the ability of a mixture of waste carrots and fruit juices (carrot, apple, mango, avocado, orange, melon and Dutch eggplant) to replace corn in broiler diet [11].

In the same view, Lira et al. mentioned that the productive performance and characteristics of the carcass and the main broiler chicken cuts are significantly affected by the addition of waste tomatoes [12]. Furthermore, several studies have been carried out on the use of medicinal plants as an ingredient for improving poultry production. In particular, Kiczorowska and al. tested the effect of the poultry diet, based on the Boswellia serrata resin (BSR) [13]. Which has been considered a good feed additive, especially by its positive effect on growth performance, dry matter content, organic matter content, and energy digestibility, as well as intestinal microbiota and the gastrointestinal tract morphology of broiler-chickens. Given the rare scientific works devoted to studying the recovery of the food waste as a feed substitute for broilers, the current study as originally aimed to encourage the valorization of this fraction of waste very abundant in

Corresponding author: latifa.mechkirrou@uit.ac.ma 
Morocco and therefore open several perspectives of its reuse in various agro-industrial sectors.

The present study, which began in 2017 in Oujda in the eastern of Morocco, aimed to test the nutritional value of a poultry Lab-Prepared Feed (LPF) from kitchen food waste, after their stabilization, sanitation, and granulation, compared to other compound foods marketed as poultry feeds.

\section{Material and methods}

\subsection{Lab-prepared poultry feed based on kitchen food waste (LPF)}
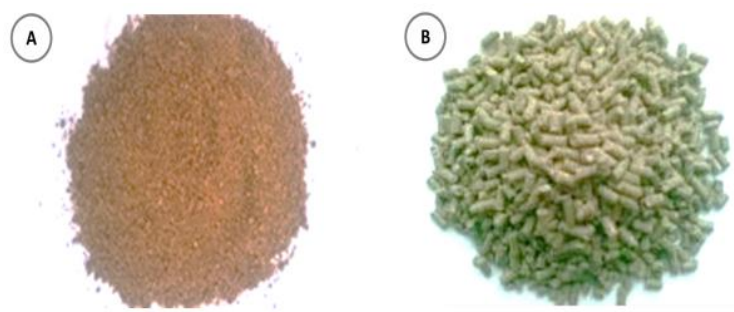

Fig. 1. The lab-prepared food (LPF) (A), the commercialized compound food (B)

Laboratory prepared food (LPF) (figure 1), intended for poultry production, is prepared from kitchen waste (leftover meals, fruits and vegetable peels) collected in many restaurants in the city of Oujda. After manual sorting of these $\mathrm{FW}$, the sorted organic fraction is initially dried in the sun. Then, the grinding of this dried product resulted in the first powder product. To enrich its nutritional value, a food supplement based on two forms of medicinal plants has been added. In addition, to facilitate the consumption of the feed by the chicks, a manual granulation by adding water is carried out as a first step. To obtain the novel food, these granules are dried in the sun until they reach a stable mass (Figure 2).

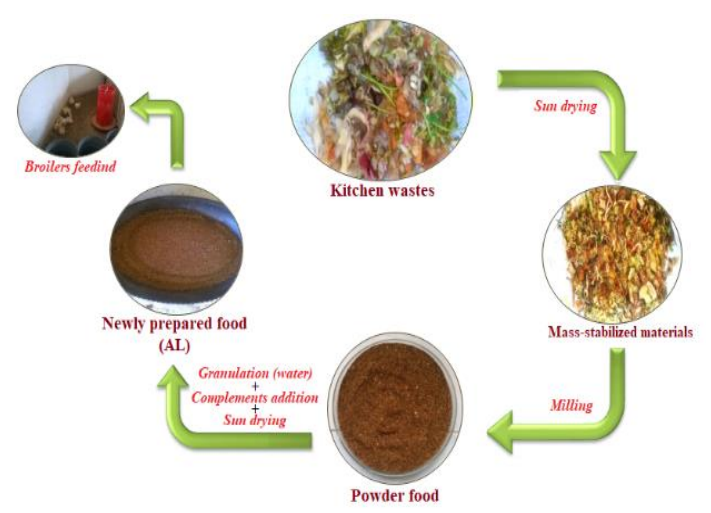

Fig. 2. Lab manufacturing steps of the lab-prepared food (LPF)

\subsection{Broilers' breeding test}

During this first comparative study, two types of foods were taken into consideration for the test (1 and 2): In each of these tests, commercialized compound foods (CCF) and the lab-prepared food (LPF) were used as poultry feed (Figure 1).

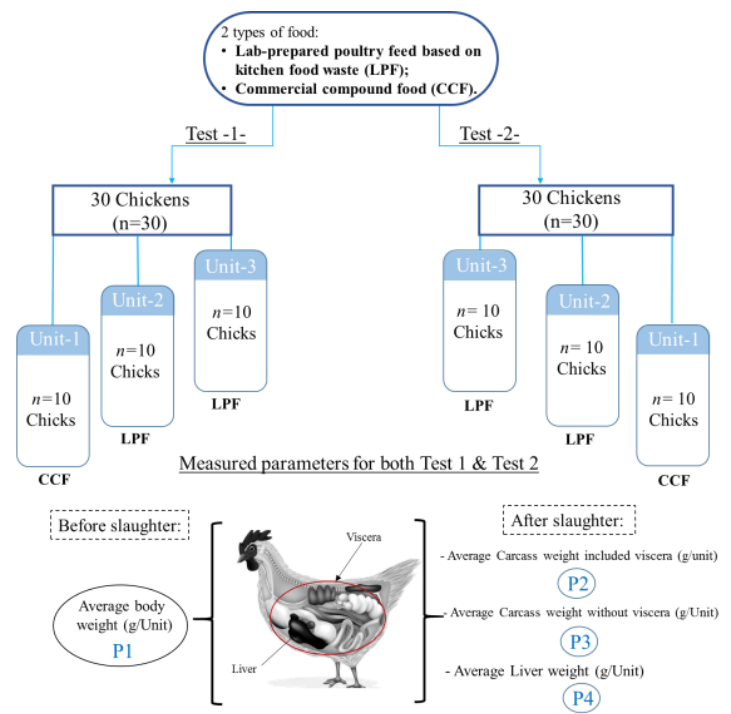

Fig. 3. Schematic of conducted Broilers Tests

Indeed, both tests were carried out on broilers in a livestock building located at the outskirts of the city of Oujda.

\subsection{Tested broilers' farming conditions}

Each of the two tests was applied on a total number of 30 10-day-old chicks (regardless of sex), for a duration of one month (June 2016 and June 2017) for the first and the second, successively to carry out these tests during the same season of the year without changing the conditions of breeding. The rearing surface area for each treatment was approximately $6.72 \mathrm{~m}^{2}$, where three experimental batches (1.7 m long, $1.5 \mathrm{~m}$ wide and $0.6 \mathrm{~m}$ high) were mounted for the easiest experiments monitoring. During the first two weeks, all poultry subgroups received the same vaccines, and treatments (following a vaccination program set by the local farmers). It is important to note that the rearing of these animals was carried out (on the ground) on a litter made up of wood shavings in a building where the rearing standards (ventilation, watering troughs, feeders, etc.) were largely respected. In addition, this rearing area was lighted only by natural daylight [14]. For each subgroup, the number of chicks reared was 10 subjects $/ \mathrm{m}^{2}$ according to the standards applied throughout the growth phase from 15 to 30 days [15]. Thereafter, these chickens were fed twice a day (at 8 am. \& $4 \mathrm{pm}$.), in cylindrical feeders that can feed up to 50 chickens. Subsequently, these chickens were fed twice a day (8 am \& $4 \mathrm{pm}$ ). Generally, to obtain the average weights of all the lots installed during the present study, the individual weight of the subjects was measured at the start. Thereafter, each group is divided into 3 subgroups of 10 chicks. These subgroups were randomly separated, and designated for experimental treatments. In addition to monitoring mortality cases, the food consumption of these chickens was measured every week by using an electronic balance (model SF-400, $\pm 10 \mathrm{~g}$ ) and this, according to the difference between the quantities of food distributed and 
recovered throughout the trial period [14]. The other parameters measured, based on changes in weight and rates of food consumed per week, were the daily weight gain (DWG), the daily individual food consumption (DIC), the consumption index (CI), carcass yield (CY) and mortality rate (MR) [14].

\subsection{Food supplement composition}

The characteristics of the food complement used to improve the weight and health performance of the reared chicks are presented in Table 1 .

Table 1. Food supplement composition \& Characteristics

\begin{tabular}{|c|c|c|}
\hline $\begin{array}{c}\text { Food } \\
\text { supplements }\end{array}$ & Composition & Characteristics \\
\hline $\begin{array}{c}\text { Powder } \\
\text { form }\end{array}$ & $\begin{array}{l}\text { - Thyme } \\
\text { leaves, } \\
\text { - bay leaf, } \\
\text { - myrtle, } \\
\text { - fennel } \\
\text { seeds }\end{array}$ & $\begin{array}{l}\text { - Stimulating effect on the } \\
\text { capacity of the digestive } \\
\text { system of the test subjects; } \\
\text { - Improved weight gain, feed } \\
\text { conversion rate and carcass } \\
\text { quality; } \\
\text { - Prevention of physical stress } \\
\text { and increased absorption of } \\
\text { nutrients in the small } \\
\text { intestine; } \\
\text { - Prevention of lower food } \\
\text { conversion rates during the } \\
\text { processing process. }\end{array}$ \\
\hline $\begin{array}{l}\text { Liquid } \\
\text { form }\end{array}$ & $\begin{array}{l}- \text { Citrus } \\
\text { fruits, } \\
\text { - Clinoptilolit } \\
\text { e essential } \\
\text { oils, } \\
\text { - Emulsifiers }\end{array}$ & $\begin{array}{l}\text { - Ability to reduce the } \\
\text { abdominal fatness; } \\
\text { - Reduction of negative } \\
\text { effects caused by } \\
\text { temperature and physical } \\
\text { stress for the subjects; } \\
\text { - Elimination of pathogens as } \\
\text { much as possible in drinking } \\
\text { water provided to chicks. }\end{array}$ \\
\hline
\end{tabular}

\section{Results and Discussion}

\subsection{Growth performance}

The measurements carried out on broilers are shown in (Figure 4A and 4B). Average weight gains were influenced very significantly by both feeding rates and the age of the chickens. Feed intake varied from one batch to another; the highest was that of the second batch (CCF), it went from $386.4 \mathrm{~g} /$ week to $1400 \mathrm{~g} /$ week for the first test and from $416.5 \mathrm{~g} /$ week at $1450 \mathrm{~g} /$ week for the second test. Followed by the second batch (LPF), in which the low consumption value was recorded between $193.8 \mathrm{~g} /$ week and $365 \mathrm{~g} /$ week for test 1 and $130.3 \mathrm{~g} /$ week at 413.5 $\mathrm{g} /$ week for test 2 (Figure 4A). Regarding weight gain for each chick at the end of this study, it is $2387 \mathrm{~g}$ and 2327.2 $\mathrm{g}$ for the compound feed (CCF), respectively, and 674.78 $\mathrm{g}$ and $689.2 \mathrm{~g}$ for the lab-prepared food (LPF) (Figure 4B). There is a similarity with the results obtained by Lira and al. who found that using tomato waste in a broiler ration during the first 28 days of fattening might cause decreased weight gain as well as worsened feed conversion of poultry. While, during the 29 to 42 day breeding period, this waste can be used without these negative effects [12]

Thus, according to Zafar and al. [16], by replacing corn with apple by-products in food ingredients, chickens gained more body weight. During the first 2 weeks of breeding, the lab-prepared food powder (LPF) was distributed to the chicks since in the initial stages of growth, due to the inability of broilers to ingest whole granules [17]. Indeed, even if the weekly consumption decreased from $193.8 \mathrm{~g}$ to $159.5 \mathrm{~g}$, the weight of each chick increased from $278 \mathrm{~g}$ to $412.9 \mathrm{~g}$. This is probably due to the food's acidic content, such as tryptophan, lysine and threonine, which increases the palatability of diets. Certainly, the addition of waste juice mixture increased the feed consumption of broilers [11]. Whereas for the last two weeks of the test, because the food is granulated, consumption reached up to $365 \mathrm{~g} /$ week and the weight was $674.78 \mathrm{~g} / \mathrm{chick}$, which improved the performance of the chickens by giving a consumption index IC of 1.41, which is the same as that obtained with industrial compound food.

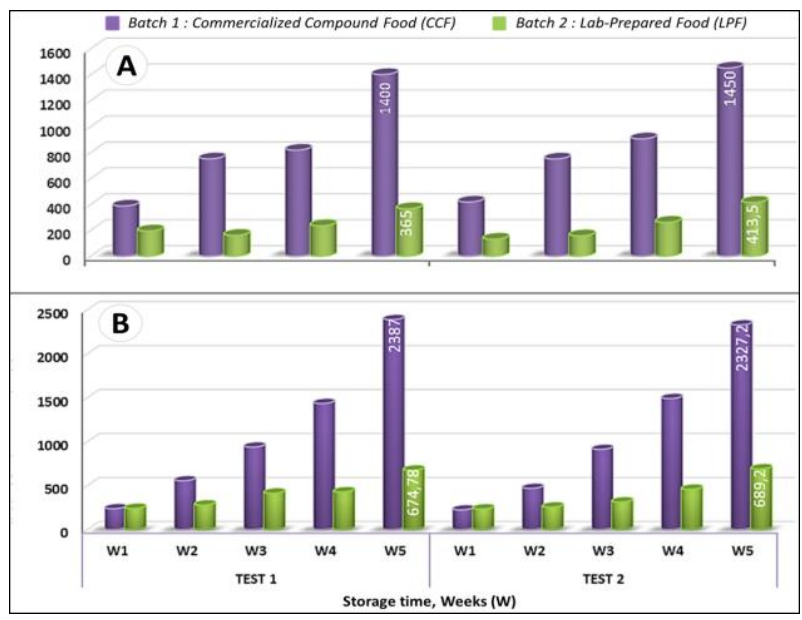

Fig. 4. Average feed consumption in (g) per chick per week (A), average weight gain in (g) per chick (B) per week.

Similar results have been reported by [18, 19], which confirm that broilers fed on granulated diets have better performances. In addition, weight gain and intake are affected by both feed form and particle size [20]. However, Hussar and al. reported that pellet diets did not affect the performance of chicks between 7 and 14 days of age [21], while Juin and al., reported that when using commercial food, the weight gain was more advantageous due to the use of raw materials containing different additives, which is of quality still in question [22]. In general, feeding with the laboratory feed (LPF) appears to be more favorable and cost-effective (Figure 4A) [12]. Furthermore, experiences clearly show that the addition of food supplements based on medicinal plants (powder and liquid) helps improve weight gain and reduce physical stress [13]. In addition, to have good profitability, it is recommended to extend the breeding period since the new feed (LPF) does not contain chemicals which help the acceleration of weight gain. 


\subsection{Characteristics of the Carcass and liver}

Animal performance was determined by calculating the average of each experimental unit after all chicks are assessed, which gives a number of reproductions $\mathrm{n}=30$ $(100 \%)$. Furthermore, the carcass, which is used for determining the feed cost [18], is measured at the age of 42 days. Concerning the carcass yield, it was determined from the weight of the hot eviscerated carcass in relation to the individual body weight measured before slaughter [23]. The results found in chicks fed with two different feeds are recorded in Table 2.

Table 2. Average carcass and liver weight measured for slaughtered broilers.

\begin{tabular}{|c|c|c|c|c|}
\hline & \multicolumn{2}{|c|}{ CCF } & \multicolumn{2}{|c|}{ LPF } \\
\cline { 2 - 5 } & $\frac{\text { Test 1 }}{(\mathrm{n}=10)}$ & $\frac{\text { Test 2 }}{(\mathrm{n}=10)}$ & $\frac{\text { Test 1 }}{(\mathrm{n}=20)}$ & $\frac{\text { Test 2 }}{(\mathrm{n}=20)}$ \\
\hline $\begin{array}{c}\text { Average Carcass } \\
\text { weight included } \\
\text { viscera (g) }\end{array}$ & 1746 & 1674 & 400 & 315 \\
\hline $\begin{array}{c}\text { Average Carcass } \\
\text { weight without } \\
\text { viscera (g) }\end{array}$ & 1358 & 1310 & 270 & 212.6 \\
\hline $\begin{array}{c}\text { Average Liver } \\
\text { weight (g) }\end{array}$ & 45 & 43.4 & 14 & 11 \\
\hline
\end{tabular}

It is clear that the use of the lab-prepared food (LPF) has led to obtaining carcasses with significantly lower weights compared to those obtained using the compound food and the weight of the liver has also decreased. Indeed, Lira et al., by adding tomato waste in the poultry diet, produced the same results, in particular up to the first 28 days of rearing [12], whereas, Zafar and al. indicated that replacing corn with apple byproducts in food ingredients increased the carcass weight [16].

\subsection{Zoo-technical performances}

According to Table 2 which shows the set of zootechnical parameters of broilers, it turns out that the consumption index (CI) obtained indicates that the subjects who received a ration based on the lab-prepared food (LPF) (Table 2) were not affected in comparison with the control subjects, which is similar to those obtained by Kwari and al. [24]. Thus, it confirms the same valuation of food in batches fed with LPF as well as the control subjects [25].

Table 3. Zoo technical performances of broilers for tests 1 and

\begin{tabular}{|c|c|c|c|r|}
\hline & \multicolumn{2}{|c|}{ CCF } & \multicolumn{2}{c|}{ LPF } \\
\hline & $\frac{\text { Test 1 }}{(\mathrm{n}=10)}$ & $\frac{\text { Test 2 }}{(\mathrm{n}=10)}$ & $\frac{\text { Test 1 }}{(\mathrm{n}=20)}$ & $\frac{\text { Test 2 }}{(\mathrm{n}=20)}$ \\
\hline $\mathbf{C I}^{\mathbf{1}}$ & 01.40 & 00.67 & 01.41 & 00.56 \\
\hline $\mathbf{M}^{\mathbf{2}}$ & 00.00 & 00.00 & 10.00 & 00.00 \\
\hline $\mathbf{A D G}^{\mathbf{3}}$ & 76.80 & 75.13 & 15.55 & 16.30 \\
\hline $\mathbf{C Y}^{\mathbf{4}}$ & 56.89 & 66.79 & 40.01 & 41.23 \\
\hline $\begin{array}{l}{ }^{I} \text { Consumption indices; } \\
{ }^{4} \text { Carcass } \text { Mield; }\end{array}$ \\
\hline
\end{tabular}

In addition, in chickens fed with LPF, the ADG is very low $(15.55 \%$ to $16.3 \%)$, while the best ADG are obtained for broilers fed with CCF, which varies between $76.8 \%$ and $75.13 \%$ at the end of the tests. The results obtained are opposite to those of Rizal and al. reporting that the ADG has been highly affected by the increased mixing of waste juices in broiler diets [11]. Regarding the carcass yield (CY) value, it indicates that the use of LPF gave low yields, varying between $40.01 \%$ and $41.23 \%$, compared to chickens fed CCF (56.89\% and $66.79 \%)$, successively for the first and second tests. Indeed, Lira and al. obtained different results, according to their study; yields were not changed by the use of tomato waste in poultry feed during the first 28 days [12].

\section{Conclusion}

Food residues represent an important part of the produced household waste. This waste mainly consists of fruit and vegetable waste, leftover meals, etc. They exhibit biomass potential and precious solutions to improve animal nutrition. Besides, the nutritional composition of the feed ingredients and the formulations used are important for the nutrition and growth of chicks. Indeed, according to this comparative study, the new food prepared from food waste produced in restaurants could help stimulate poultry production at a lower cost and ensure a balanced diet for the public. What encourages formulating, in next studies, the promotion of this recovering method, in a complete proposal on the production feasibility as food for broilers, while respecting the standards recommended for poultry.

\section{References}

1. M. Arabi, M. Sbaa, M. Vanclooster, A. Darmous, J. Ecol. Eng, 21, 8 (2020)

2. K.E. Koledzi, G. Baba, G. Matejka, G. Ludington, K.N. Segbeaya, G. Tchangbedji, A. Pilabana, G. Morizot, Déchets sci. Tech. - rev. Franc. Écol. Ind., 62 (2012)

3. M. Belmakki, E.H. Bartali, H. Xiaoru, A. Bjerre, Moroccan J. Agron. Vet. Sci, 3, 9 (2015)

4. F. Karouach, M. Bakraoui, Y. El Gnaoui, N. Lahboubi, H. El Bari, Energy Rep, 6, 5(2020)

5. Y. El Gnaoui, F. Karouach, M. Bakraoui, M. Barzb, H. El Baria, Energy Rep, 6, 6 (2020)

6. A.J. García, M.B. Esteban, M.C. Marquez, P. Ramos, Waste Manage, 25, 8 (2005)

7. J.D. Ferguson, Mater. Sci. Mater. Eng, 15 (2019)

8. E.K.H.J. Zu Ermgassen, B. Phalan, R.E. Green, A. Balmford, Food Policy, 58, 14 (2016)

9. R. Salemdeeb, E. K. H. J. zu Ermgassen, M. H. Kim, A. Balmford, A. Al-Tabbaa, J. Cleaner Prod, 27 (2016)

10. H. El Ouahabi, L. Tahri, A. Serghini, A. Belaouchou, M. Fekhaoui, Int. J. Innov. Appl. Stud., 17, 4 (2016)

11. Y. Rizal, M.E. Mahata, M. Andriani, G. Wu, J. nutr. food eng., 4, 8 (2010) 
12. R.C. Lira, C.B.V. Rabello, M.C.M.M. Ludke, P.V. Ferreira, G.R.Q., Lana S.R.V., Lana, Rev. brasil. Zootec, 39, 5 (2010)

13. B. Kiczorowska, A.R.M. Al-Yasiry, W. Samolińska, A. Marek E. Pyzik, Livestock Sci, 191 (2016)

14. S.B. Ayssiwede, R. Missoko-Mabeki, A. Mankor, A. Dieng, M.R. Houinato, C.A.A.M. Chry-Sostome, M. Dahouda, A. Missohou, J.L. Hornick, Revue Méd. Vét. 163, 12 (2012)

15. ANSEJ. Aviculture - Élevage des poules pondeuses Fiche technique. 8 (2010)

16. F. Zafar, M. Idrees, Z. Ahmed, Pakistan J. Physiol, 1, 1-2 (2005)

17. S. Cerrate, Z. Wang, C. Coto, F. Yan, P.W. Waldroup, J. Appl. Poultry Res, 18, 3 (2009)

18. M.R. Abdollahi, V. Ravindran, B. Svihus, Anim. feed sci. technol., 179 (2013)
19. A. Massuquetto, J.F. Durau, V.G. Schramm, M.V. Teixeira Netto, E.L. Krabbe, A. Maiorka, J. Appl. Poultry Res, 27, 1(2018)

20. L. Mingbin, Y. Lei, W. Zhengguo, A. Sha, W. Miaomiao, L. Zunzhou, Animal Nutrition, 1, 3 (2015)

21. N. Hussar, A.R. Robblee, Poultry Sci, 41 (1962)

22. H. Juin, C. Bordeaux, D. Feuillet, A. Roinsard, 11ème JRA-FG, Tours. (2015)

23. R. Bakhshalinejad, A. Hassanabadi, R.A. Swick, Anim. Nutr, 5 (2019)

24. I.D. Kwari, S.S. Diarra, B. Saleh, P.R. Bovoa, O.A. Ramat, D. Tochukwu, Int. J. Poultry Sci, 10, 8 (2011)

25. J.R. Kana, A.D. Hassan, T.R. Ngouana, K.H. Mube, A. Teguia, Y. Tefack, H.R. Zambou, Int. J. Biol. Chem. Sci, 9, 5 (2015) 